\title{
On Thermal and State-of-Charge Balancing using Cascaded Multi-level Converters
}

\author{
Faisal Altaf ${ }^{\dagger}$, Lars Johannesson ${ }^{*}, * *$, and Bo Egardt ${ }^{*}$ \\ $\dagger^{* *}$ Dept. of Signal and Systems, Chalmers University of Technology, Gothenburg, Sweden \\ ${ }^{* *}$ Viktoria Swedish ICT, Gothenburg, Sweden
}

\begin{abstract}
In this study, the simultaneous use of a multi-level converter (MLC) as a DC-motor drive and as an active battery cell balancer is investigated. MLCs allow each battery cell in a battery pack to be independently switched on and off, thereby enabling the potential non-uniform use of battery cells. By exploiting this property and the brake regeneration phases in the drive cycle, MLCs can balance both the state of charge $(\mathrm{SoC})$ and temperature differences between cells, which are two known causes of battery wear, even without reciprocating the coolant flow inside the pack. The optimal control policy (OP) that considers both battery pack temperature and $\mathrm{SoC}$ dynamics is studied in detail based on the assumption that information on the state of each cell, the schedule of reciprocating air flow and the future driving profile are perfectly known. Results show that OP provides significant reductions in temperature and in $\mathrm{SoC}$ deviations compared with the uniform use of all cells even with uni-directional coolant flow. Thus, reciprocating coolant flow is a redundant function for a MLC-based cell balancer. A specific contribution of this paper is the derivation of a state-space electro-thermal model of a battery submodule for both uni-directional and reciprocating coolant flows under the switching action of MLC, resulting in OP being derived by the solution of a convex optimization problem.
\end{abstract}

Key words: Hybrid electric vehicles, Multi-level converter, Batteries, Cell balancing, Thermal balancing, Convex optimization

\section{INTRODUCTION}

Although battery technology has evolved significantly during the last decade, batteries of both plug-in hybrid electric vehicles (PHEVs) and electric vehicles (EVs) contribute a large percentage of the total vehicle cost. Consequently, the success of PHEVs and of EVs depends on the development of a battery that will not wear out prematurely to avoid additional battery replacement during the expected lifespan of the vehicle. The battery pack (BP) of EVs/HEVs/PHEVs is built from a large number of small cells connected in series and parallel to meet both the traction power demand and the electric range requirement. Depth of discharge (DoD) is one of the most important factors that determine degradation of battery cells, such as battery operation at higher DoD shorten the cycle life and vice versa [1]-[4]. Therefore, the cycle life of a battery is significantly short when it undergoes full charge-discharge cycles, whereas the cycle life becomes significantly longer when it only undergoes partial charge-discharge cycles [5]. In a

Manuscript received Jan. 28, 2013; revised May. 20, 2013 Recommended for publication by Associate Editor Jin Hur.

†Corresponding Author: faisal.altaf@chalmers.se

Tel: +46-3177-21774, Chalmers University of Technology

${ }^{\dagger}$ Dept. of Signal and Systems, Chalmers Univ. of Tech., Sweden

${ }^{* *}$ Viktoria Swedish ICT, Sweden pack with state of charge (SoC) and capacity deviations among its cells, some of the cells undergo charge-discharge cycles at higher DoD than others. Consequently, these cells may reach their end-of-life (EOL) sooner. Thus, maintaining a perfect balance between SoC and DoD of each cell in the battery pack is crucial in prolonging battery life. This balance can be achieved by either passive or active balancing schemes based on various topologies of switched capacitive and resistive circuits, as illustrated in [6]-[9]. The main principle of all active balancing schemes is to transfer the charge from cells with higher $\mathrm{SoC}$ to cells with lower $\mathrm{SoC}$ by using switched capacitors that act as intermediate storage banks. Passive balancing schemes typically utilize differences in cell voltage to burn excess charge in resistor banks.

Aside from DoD, cell temperature is known to have a strong effect on battery wear, such as hotter cells degrade more quickly than colder cells [10]-[13]. More importantly, the presence of a few overheated cells can wear out the entire battery prematurely. The temperature imbalance between cells is due to variation in internal resistances, in the temperature gradient in the coolant due to convective heat transfer inside the battery pack, and the non-uniform external local thermal disturbances [13], [14]. The lifespan of a Li-Ion cell is reportedly reduced by two months for each degree increase in operating temperature from $30{ }^{\circ} \mathrm{C}$ to 
$40{ }^{\circ} \mathrm{C}[15]$. However, when temperature increases beyond $40{ }^{\circ} \mathrm{C}$, the cycle life of a battery decreases drastically.

Forced convection cooling is typically used to maintain batteries within the recommended temperature range. However, this method cannot compensate for the temperature gradient along the coolant fluid stream. Cells that are closer to the air inlet will be cooler than those further down the coolant stream. Reciprocating air flow (RF) was proposed in [10] and in [14] as a mean to reduce the effects of the temperature gradient in the coolant stream. However, in the present study, it is shown that cells continue to suffer from non-uniform local heated spots in the presence of parameter variation and local disturbances.

Considering the aforementioned causes of battery wear, the battery management unit (BMU) should balance both SoC and temperature differences between cells. Therefore, this paper investigates the MLC-based active cell balancing scheme that allows hot cells to be bypassed, consequently balancing both SoC and temperature without the need for RF.

Cascaded MLCs [16], [17] had been investigated for electric drives in HEVs and in EVs in [18], [19]. MLC consists of $n$ cascaded H-bridges (HBs) with an isolated battery cell for each HB. In this paper, the combination of HB and a battery cell is referred to as a power cell (PC). MLCs in EV/HEV/PHEV application are intended to reduce inverter losses and total harmonic distortion in the generated waveform for the electric machine. The usual switching strategy in motor drive applications of MLCs is the phase-shifted pulse width modulation (PS-PWM) technique that achieves the uniform use of cascaded cells [16], [17].

However, MLC presents an additional advantage as the cells need not be uniformly used over a time window of one or several voltage waveforms. By non-uniformly using the cells and by exploiting the brake regeneration phases in the drive cycle, an MLC cell balancer can balance both SoC and temperature differences. In this study, the PS-PWM scheme is referred to as the uniform duty cycle operation (UDCO), whereas the optimal scheme that controls the duty cycle of each $\mathrm{PC}$ to balance both SoC and temperature is referred to as optimal control policy (OP). The potential benefit of using MLC to balance both SoC and temperature of battery cells under a uni-directional flow (UF) has been thoroughly investigated and compared with that of UDCO [20]. Thus, the main contribution of the current study is to investigate OP under $\mathrm{RF}$, and then to compare the results in detail with those of OP under UF. OP is calculated based on the assumption of perfect information of the SoC and the temperature of each cell, as well as of the future driving. This paper examines whether OP provides more significant improvements compared with UDCO under UF and RF and whether RF presents any potential benefits for OP-based active cell balancing.

For simplicity, this study employs a DC machine as the electric machine and models the cells by resistive circuits. Moreover, the simulation study focuses on an air-cooled battery

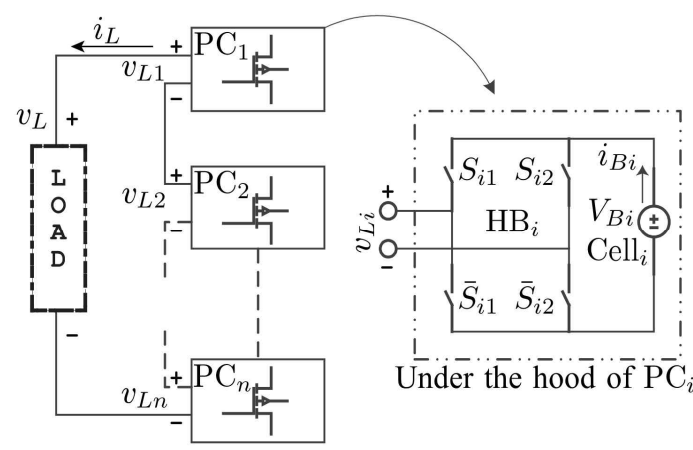

Fig. 1. Block diagram of a single-phase cascaded HB MLC.

sub-module (BSM) with a string of five series-connected cells. The coolant flow is assumed to be laminar with known inlet temperature and speed. In [21], only one configuration of the five-cell string was studied to evaluate the performance of the MLC-based cell balancer. A similar method was adopted in the present study. However, a more thorough analysis was conducted to carefully assess the performance of the cell balancer. For purpose of evaluation, two different variants of the five-cell string were studied. In the first variant, the higher resistance cell is located at the end of the string in the downstream of the coolant fluid. In the second variant, the higher resistance cell is located in the middle of the string. The resistance of the thermally exposed cell was assumed to be almost 50\% higher than that of others cells when comparing the performance of UDCO and OP under both UF and RF.

Besides the simulation results and the evaluation of MLC as a cell balancer, another important contribution of this paper is the detailed derivation of a state-space electro-thermal model of BSM under the switching action of MLC under UF and RF. The model was formulated in such a way that a convex optimization problem yields OP under a perfectly known future driving. This model can be used in future research in deciding the duty cycle in a receding horizon model predictive control scheme [22] based on the best available prediction of future driving.

The paper is organized as follows. Section II introduces the basic function of MLC. Section III presents the detailed electro-thermal modeling of BSM under the switching action of MLC. The optimization problem and the numerical solution method are described in Section IV. Section V presents the simulation results and the comparison between OP and the UDCO schemes under both UF and RF. A detailed discussion on the simulation results is provided in Section VI. The conclusions are given in Section VII.

\section{Multi-LeVel CONVERTERs OVERVIEW}

This section provides a short introduction on single-phase MLC. In contrast to two-level converters that consist of a single large battery connected with a single HB, MLC as shown in Fig. 1 has several series-connected PCs in which each PC contains an HB and the independent battery cell.

$\mathrm{HB}$, which consists of two half-bridges, is a switch mode 
dc-dc power converter [23] that produces a four-quadrant controllable dc output using four switches, namely, $S_{i 1}, S_{i 2}$, $\bar{S}_{i 1}$, and $\bar{S}_{i 2}$, as shown in Fig. 1. The MoSFETs are normally used for these switches. To avoid a shoot-through problem, only one of the switch pairs, $\left(S_{i 1}, \bar{S}_{i 2}\right),\left(S_{i 2}, \bar{S}_{i 1}\right),\left(S_{i 1}, S_{i 2}\right)$, or $\left(\bar{S}_{i 1}, \bar{S}_{i 2}\right)$, is switched on at a time. $\left(S_{i 1}, \bar{S}_{i 2}\right)$ generates a positive output voltage $v_{L i}$ from $P C_{i},\left(S_{i 2}, \bar{S}_{i 1}\right)$ generates a negative $v_{L i}$, and both $\left(S_{i 1}, S_{i 2}\right)$ and $\left(\bar{S}_{i 1}, \bar{S}_{i 2}\right)$ generate $v_{L i}=0$. Therefore, the following three modes of operation can be defined for each $P C_{i}$ depending on the switch pair that is switched on: Mode-1 $\left(v_{L i}>0\right)$, Mode-2 $\left(v_{L i}<0\right)$, and Mode-3 $\left(v_{L i}=0\right)$. To model these three modes of operation, $s_{i j}(t)=1$ is defined as the ON-State and $s_{i j}(t)=0$ is defined as the OFF-State of the switch $S_{i j}$, where ' $i$ ' corresponds to $P C_{i}$ and $j \in\{1,2\}$ denotes one of the two half-bridges in HB. Therefore, the switching function $s_{i}(t)$ for Cell $l_{i}$ can be defined as

$$
s_{i}(t)=s_{i 1}(t)-s_{i 2}(t)=\left\{\begin{array}{cc}
1, & \text { Mode }-1 \\
-1, & \text { Mode }-2 \\
0, & \text { Mode }-3
\end{array}\right.
$$

Thus, all three modes of HB can be defined in terms of $s_{i}(t)$. The switching vector $s(t)=\left[\begin{array}{lll}s_{1}(t) & \cdots & s_{n}(t)\end{array}\right]^{T}$ contains the switching functions for all $n$ PCs inside MLC. With the assumption of an ideal switch behavior, the ohmic and the switching losses can be ignored. Therefore, the input and the output of HB are related through the switching function $s_{i}(t)$, as shown in Fig. 2. Thus, the current in $\mathrm{Cell}_{\mathrm{i}}$ is given by

$$
i_{B i}(t)=i_{L}(t) s_{i}(t)
$$

As a result of the series connection, the same load current $i_{L}$ passes through each PC. However, the direction of the current passing through Cell ${ }_{i}$ depends on the selection of switches and on the direction of load current $i_{L}$. Similarly, the voltage output from each $P C_{i}$ is defined by $v_{L i}(t)=V_{B i}(t) s_{i}(t)$. Hence, the total voltage output from MLC can be written as the sum of the voltage output from each $P C_{i}$ as given below.

$$
v_{L}=\sum_{i=1}^{n} v_{L i}=\sum_{i=1}^{n} V_{B i}(t) s_{i}(t)
$$

The number of voltage levels that MLC generates depends on the number of PCs and on the terminal voltage $V_{B i}$ of Cell $1_{\mathrm{i}}$. If the terminal voltage of all cells is the same, MLC can then generate $L=2 n+1$ different voltage levels $\left(v_{L}\right)$.

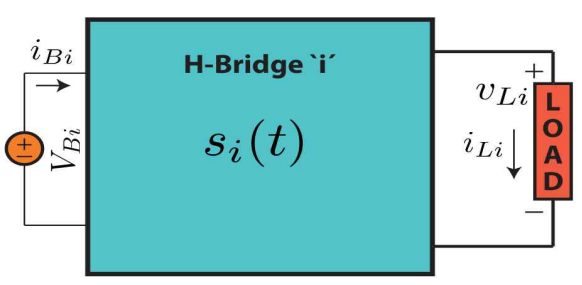

Fig. 2. Switching model of HB.

\section{MOdeling OF THE CELl BALANCING SySTEM WITH RF}

The block diagram of the cell balancing system for RF and for UF is shown in Fig. 3. MLC is capable of generating the same output voltage level $v_{L}$ in several ways by using different combinations of the three modes for various PCs, providing redundancy in generating the same load voltage through numerous possible switch combinations. This redundancy adds an extra degree of freedom (DoF) that is utilized in this paper to design the optimal control signal $u_{i}$ for $\mathrm{Cell}_{\mathrm{i}}$. Consequently, SoC and temperature differences between cells are kept within a certain zone, while satisfying all other operating requirements. In this section, a switching model and an averaged state-space model of a PC is derived based on the assumption that the load is a DC machine. Finally, the complete state-space model for $n$ PCs is developed.

\section{A. Switching Model of a Power Cell}

In this subsection, the electro-thermal model of a switched battery cell under RF is derived. Each $P C_{i}$ is assumed to contain only one $\mathrm{Cell}_{\mathrm{i}}$. The dynamics of cell temperature depends on several factors such as coolant properties, cell material properties, cell placement, and battery pack configuration. In [14], the forced-convection cooled battery pack was modeled by the lumped capacitance thermal model and by the flow network model (FNM). In the said study, the battery pack was configured as $n_{s} S n_{p} P$ that represents $n_{p}$ parallel strings, with each string, called a battery module, containing $n_{s}$ cells connected in a series. A sufficient amount of free space is present between the cells to allow streams of laminar flow of the coolant (air). A configuration of the battery pack, Li-Ion cells, and the air properties adopted in the present paper are similar to those in [14]. Various coefficients for the thermal and the physical properties of the cell and of the air used in this study are listed in Table I. Details are provided in [14]. $C_{N i}[A h]$ represents the nominal capacity of $\mathrm{Cell}_{\mathrm{i}}$, and $R_{u i}\left[K W^{-1}\right]$ represents the convection thermal resistance for $\mathrm{Cell}_{\mathrm{i}}$ that depends on the geometry of the battery cell, on the coolant fluid properties, and on the 
TABLE I

DEFINITION OF BATTERY PARAMETERS

\begin{tabular}{ll|ll}
\hline Parameters & Expression & Parameters & Expression \\
\hline$a_{s i}\left[\frac{1}{s}\right]$ & $\left(\frac{1}{C_{s i} R_{u i}}\right)$ & $b_{r i}[\Omega]$ & $R_{s i}$ \\
$a_{e i 1}\left[\frac{1}{s}\right]$ & $\left(\frac{1}{R_{i 1} C_{i 1}}\right)$ & $\alpha_{i}[$ Unitless $]$ & $R_{u i} \mathrm{C}_{\mathrm{f}}$ \\
$a_{e i 2}\left[\frac{1}{s}\right]$ & $\left(\frac{1}{R_{i 2} C_{i 2}}\right)$ & $\beta_{i}[$ Unitless $]$ & $-1+\alpha_{i}$ \\
$b_{s i}\left[\frac{\Omega K}{W s}\right]$ & $\left(\frac{R_{s i}}{C_{s i}}\right)$ & $b_{e i 2}\left[\frac{V}{s A}\right]$ & $\left(\frac{1}{C_{i 2}}\right)$ \\
$b_{e i 1}\left[\frac{V}{s A}\right]$ & $\left(\frac{1}{C_{i 1}}\right)$ & $b_{e i 3}\left[\frac{1}{A s}\right]$ & $\left(\frac{1}{3600 C_{N i}}\right)$ \\
\hline
\end{tabular}

Nusselt number, which, in turn, depends on the Reynolds number.

The coefficient $C_{s i}=\rho_{s i} c_{p s i} V_{s i}\left[J K^{-1}\right]$ represents heat capacity (amount of heat energy required to raise the temperature of Cell ${ }_{\mathrm{i}}$ by 1 Kelvin), where $\rho_{s i}$ is the density, $c_{p s i}$ is the specific heat capacity (heat capacity per unit mass of battery), and $V_{s i}\left[\mathrm{~m}^{3}\right]$ is the volume of Cell $\mathrm{i}_{\text {. The }}$ coefficient $c_{f}=\rho_{f} c_{p f} \dot{V}_{f}\left[W K^{-1}\right]$ is thermal conductance of the coolant fluid. All other quantities are shown in Fig. 4.

In this paper, only one submodule (of the battery module) that consists of $n$ series-connected battery cells is studied. First, the thermal model is derived separately for the coolant flow in each direction. The two models are then combined to create the model for RF. In this study, both RF and UF are examined and compared. Hence, the case of forward flow (i.e., from lower to higher cell index) is designated as UF for ease of reference. The thermal model proposed in [14] does not consider any power electronic switching of the battery cells. Thus, power electronic switching must be incorporated into the current framework. The previous model was modified by embedding the switching function $s_{i}(t)$ and subsequently combining it with the enhanced Thevenin equivalent electrical model, shown in Fig. 4, to derive the switching electro-thermal model of $P C_{i}$.

For forward flow, the dynamics of the surface temperature $T_{s i}[K]$ of Cell $1_{\mathrm{i}}$ in terms of $i_{L}(t)$ and $s_{i}(t)$, after substituting the value of $i_{B i}(t)$ from equation (2) into the model proposed in [14], is given by

$$
\dot{T}_{s i}=-a_{s i} T_{s i}+b_{s i} i_{L}^{2} s_{i}^{2}+a_{s i} T_{f i-1}, \quad \forall i=\{1, \cdots, n\}
$$

where the $i_{L}^{2} s_{i}^{2}$ represents the instantaneous ohmic power losses on Cell $\mathrm{i}_{\mathrm{i}}$ and $T_{f i-1}[K]$ is the temperature of temperature node ' $i-1$ ' (of the fluid element modeled by FNM) attached to Cell $\mathrm{l}_{\mathrm{i}}$ in an upstream direction. Equation (4) is not that interesting in terms of control design because it explicitly depends on the fluid node temperature $T_{f i-1}$ for

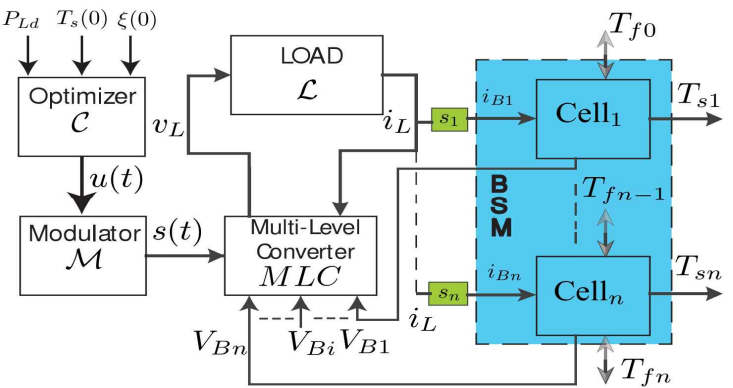

Fig. 3. Conceptual block diagram of a battery cell balancing system with RF. $T_{s}(0)$ is a vector containing the initial temperature of all cells, $\xi(0)$ is a vector containing the initial SoC of all cells, $P_{L d}$ is the demanded power for load with the known voltage and current profile, and $T_{f 0}, \cdots, T_{f n}$ represent temperatures of temperature-nodes of the coolant fluid. The subsystem inside the blue box represents BSM being balanced and the green boxes contain the switching functions for the corresponding cell.

Cell $_{i}$ that is not directly known. Therefore, this equation must be modified to remove this explicit dependency. For control design purpose, the temperature dynamics of each cell can be more appropriately modeled in terms of battery current $i_{B i}=i_{L} s_{i}$ and of the temperature $T_{f i n} \in\left\{T_{f 0}, T_{f n}\right\}$ of the coolant fluid at the inlet. To achieve this, $T_{f i-1}$ is eliminated from equation (4) as follows. According to [14], the temperatures of the nodes ' $i-1$ ' and ' $i$ ' are related by

$$
T_{f i}=\frac{\left(T_{s i}+\beta_{i} T_{f i-1}\right)}{\alpha_{i}}, \forall i
$$

where $\alpha_{i}$ and $\beta_{i}$ are defined in Table I. Given that $T_{f 0}$ is a known quantity, then by forward recursion of equation (5), any $T_{f i}$ can be expressed as a function of the inlet fluid temperature $T_{f 0}$ and of the temperatures $T_{s 1}$ to $T_{s i}$ of the battery cells, such as

$$
\begin{aligned}
T_{f 1} & =\left(\frac{1}{\alpha_{1}}\right) T_{s 1}+\left(\frac{\beta_{1}}{\alpha_{1}}\right) T_{f 0}, \\
T_{f 2} & =\left(\frac{\beta_{2}}{\alpha_{1} \alpha_{2}}\right) T_{s 1}+\left(\frac{1}{\alpha_{2}}\right) T_{s 2}+\left(\frac{\beta_{1} \beta_{2}}{\alpha_{1} \alpha_{2}}\right) T_{f 0}, \\
T_{f 3} & =\left(\frac{\beta_{2} \beta_{3}}{\alpha_{1} \alpha_{2} \alpha_{3}}\right) T_{s 1}+\left(\frac{\beta_{3}}{\alpha_{2} \alpha_{3}}\right) T_{s 2}+\left(\frac{1}{\alpha_{3}}\right) T_{s 3} \\
& +\left(\frac{\beta_{1} \beta_{2} \beta_{3}}{\alpha_{1} \alpha_{2} \alpha_{3}}\right) T_{f 0},
\end{aligned}
$$

and so on. Therefore, the general equation for any $T_{f i}$ is written as follows:

$$
T_{f i}=a_{f i 1}^{(1)} T_{s 1}+a_{f i 2}^{(1)} T_{s 2}+\cdots+a_{f i i}^{(1)} T_{s i}+b_{f i}^{(1)} T_{f 0}
$$


where

$$
\begin{gathered}
a_{f i i}^{(1)}=\left(\frac{1}{\alpha_{i}}\right), \quad b_{f i}^{(1)}=\left(\frac{\prod_{k=1}^{i} \beta_{k}}{\prod_{k=1}^{i} \alpha_{k}}\right), \quad \forall i \geq 1 \\
a_{f i j}^{(1)}=\left(\frac{\prod_{k=(j+1)}^{i} \beta_{k}}{\prod_{k=j}^{i} \alpha_{k}}\right), \forall i>j, \quad a_{f i j}^{(1)}=0, \quad \forall i<j
\end{gathered}
$$

Using equation (7) in (4), the thermal dynamics of the battery cells can be rewritten as follows:

$$
\dot{T}_{s i}=a_{t i 1}^{(1)} T_{s 1}+\cdots+a_{t i n}^{(1)} T_{s n}+b_{s i} i_{L}^{2} s_{i}^{2}+b_{t i}^{(1)} T_{f 0}
$$

where:

$$
\begin{gathered}
a_{t i i}^{(1)}=-a_{s i}, \forall i \geq 1 \\
a_{t i j}^{(1)}=\left(\frac{\prod_{k=(j+1)}^{(i-1)} \beta_{k}}{\prod_{k=j}^{(i-1)} \alpha_{k}}\right) a_{s i}, \forall i>j, \quad a_{t i j}^{(1)}=0, \forall i<j \\
b_{t i}^{(1)}=\left(\frac{\prod_{k=1}^{(i-1)} \beta_{k}}{\prod_{k=1}^{(i-1)} \alpha_{k}}\right) a_{s i}, \forall i \geq 1
\end{gathered}
$$

Analogous to the forward flow case, the thermal dynamics of $\mathrm{Cell}_{\mathrm{i}}$ is derived for the reverse coolant flow (i.e., from higher to lower cell index). The result is given below

$$
\dot{T}_{s i}=a_{t i 1}^{(2)} T_{s 1}+\ldots+a_{t i n}^{(2)} T_{s n}+b_{s i} i_{L}^{2} s_{i}^{2}+b_{t i}^{(2)} T_{f n}
$$

where $T_{f n}$ is the temperature of the inlet fluid entering BSM from the $\mathrm{Cell}_{\mathrm{n}}$ side. The other coefficients are defined as follows:

$$
\begin{gathered}
a_{t i i}^{(2)}=a_{t i i}^{(1)}, \quad \forall i \geq 1, \quad b_{t i}^{(2)}=b_{t(n-i+1)}^{(1)}, \quad \forall i \geq 1 \\
a_{t i j}^{(2)}=a_{t j i}^{(1)}, \quad \forall i<j, \quad a_{t i j}^{(2)}=0, \quad \forall i>j
\end{gathered}
$$

The electrical equivalent model of a battery cell is shown in Fig. 4. This model is an enhanced Thevenin model with two time constant behaviors [24]-[26]. The dynamic model for this circuit is given by

$$
\begin{gathered}
\dot{V}_{i 1}=-a_{e i 1} V_{i 1}+b_{e i 1} i_{L} s_{i}, \\
\dot{V}_{i 2}=-a_{e i 2} V_{i 2}+b_{e i 2} i_{L} s_{i}, \\
\dot{\xi}_{i}=-b_{e i 3} i_{L} s_{i}, \\
V_{B i}=f\left(\xi_{i}\right)-V_{i 1}-V_{i 2}-b_{r i} i_{L} s_{i}
\end{gathered}
$$

where $i_{B i}$ is the current flowing through $\mathrm{Cell}_{\mathrm{i}}$ and $\xi_{i}$ is the normalized SoC of Cell ${ }_{\mathrm{i}} \cdot \xi_{i} \in[0,1]$ is a unit-less quantity. $V_{i 1}$ and $V_{i 2}$ are the voltages across capacitors $C_{i 1}$ and $C_{i 2}$, respectively, and $V_{B i}$ is the output voltage of Cell $l_{\mathrm{i}}$. The SoC-dependent open circuit voltage is given by $V_{o c i}=f\left(\xi_{i}\right)$,

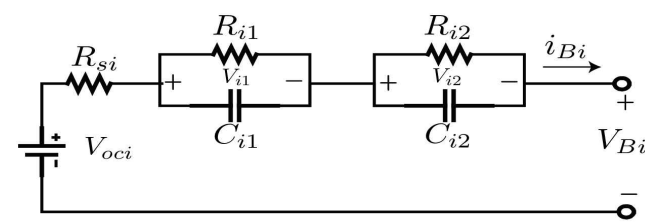

Fig. 4. Electrical model of a battery cell.

where $f:[0,1] \rightarrow \Re_{0}^{+}$is a function of SoC. Equations (10) to (20) describe the switched behavior of the battery under the switching action of MLC, in terms of the load current $i_{L}(t)$ and of the switching function $s_{i}(t)$. Therefore, this model can be considered as a switching model of $P C_{i}$.

\section{B. Averaged State-Space Model of PC}

Cell balancing can be formulated as an optimization problem using two approaches. In the first approach, cell operation is optimized by directly using the switching function $s_{i}(t)$ as an optimization variable for $\mathrm{Cell}_{\mathrm{i}}$. The switching function $s_{i}(t)$ in equation (1) can only attain values from the discrete set $\{-1,0,1\}$. Hence, the computed optimal control is a discrete-valued signal. In this case, the system is normally modeled as a switched system with various modes of operation, and the optimization problem therefore becomes combinatorial that is normally difficult to solve because of its non-convex nature. However, the aim of this study is to evaluate OP, which necessitates a model with a real-valued control signal because such models are far easier to handle in optimization problems than those with discrete-valued signals. Hence, the second control approach is used instead, wherein the battery duty cycle $u_{i} \in[-1,1]$, which is the average of the switching input function $s_{i}(t)$, is used as optimization variables for Cell $\mathrm{i}_{\mathrm{i}}$. The optimizer computes a control vector signal $u$ that contains duty cycles $u_{i} \in[-1,1]$ for each $P C_{i}$. Note that the negative duty cycle means operation in Mode-2 . The computed control $u$ is then fed to the modulation block $\mathrm{M}$, which then generates an appropriate switching function $s_{i} \in s(t)$ for each PC. Given that the switching model (10)-(20) involves discrete-valued signals $s_{i}(t)$, these signals must be transformed into real-valued averaged signals to modify the system model (10)-(20) accordingly. The use of averaging is justified by the fact that, in most cases, the switching frequency $F_{s}$ inside the modulator $\mathrm{M}$ is significantly higher than the bandwidth $f_{L}$ of the system. Thus, by assuming that $F_{S} \gg f_{L}$ and by employing the two-time scale separation principle [27], the concept of averaging can be employed [28] [29]. In other 
words, the system response is assumed to be determined predominantly by the duty cycle $u_{i}(t) \in[-1,1]$ or the average of the switching input function $s_{i}(t)$. In addition, careful derivation is required given that the switching model involves certain bilinear and quadratic terms. In this section, the averaged model is derived in detail by averaging each signal over one switching cycle. The following assumptions are made in deriving the average quantities:

Assumption 1: The switching function can only attain values either from set $\{0,1\}$ or from $\{0,-1\}$ during any switching cycle of period $T_{s}$. This assumption implies that it is not allowed to charge and to discharge the battery cell during the same switching cycle.

Assumption 2: The load current $i_{L}(t)$ remains fairly constant during any switching cycle. This assumption is justified based on the discussion above.

Assumption 3: All internal electrical states $V_{i 1}=\bar{V}_{i 1}$, $V_{i 2}=\bar{V}_{i 2}$, and $\xi_{i}=\bar{\xi}_{i}$, as well as terminal voltage $V_{B i}$, remain fairly constant during the switching cycle.

Based on these assumptions, the average of the switching function $s_{i}(t)$, which is also called the duty cycle, is given by

$$
u_{i}(t)=\bar{s}_{i}(t)=\frac{1}{T_{s}} \int_{t-T_{s}}^{t} s_{i}(t) d t= \pm \frac{T_{o n}}{T_{s}}
$$

where $T_{o n}$ is the ON time of a switch during any switching interval. This equations shows that $u_{i}(t)$ can attain any continuous real value in the interval $[-1,1]$, depending on the value of $T_{o n}$. All other averaged signals can be defined in terms of $u_{i}(t)$ and $i_{L}(t)$ as follows:

$$
\begin{gathered}
\bar{i}_{B i}(t)=u_{i} i_{L}, \quad i_{B r_{i}}^{2}=\left|u_{i}\right| i_{L}^{2} \\
\bar{v}_{L i}=\left(f\left(\bar{\xi}_{i}\right)-\bar{V}_{i 1}-\bar{V}_{i 2}\right) u_{i}-b_{r i}\left|u_{i}\right| i_{L}
\end{gathered}
$$

where $\bar{i}_{B i}$ is the average current flowing through Cell ${ }_{\mathrm{i}}$ during interval $T_{s}, i_{B r_{i}}$ is the root mean square (RMS) current that incurs equivalent ohmic loss across Cell $_{\mathrm{i}}$ during one switching cycle, and $\bar{v}_{L i}$ is the average output voltage from $P C_{i}$ during period $T_{S}$ of any switching cycle. [20] presents the detailed derivation of all the averaged variables. Using the averaged quantities, the averaged model of $P C_{i}$ is written as follows:

$$
\begin{gathered}
\dot{\bar{T}}_{s i}=a_{t i 1}^{(\sigma)} \bar{T}_{s 1}+\cdots+a_{t i n}^{(\sigma)} \bar{T}_{s n}+b_{s i} i_{L}^{2}\left|u_{i}\right|+b_{t i}^{(\sigma)} T_{f i n} \\
\dot{\bar{V}}_{i 1}=-a_{e i 1} \bar{V}_{i 1}+b_{e i 1} i_{L} u_{i}
\end{gathered}
$$

$$
\begin{gathered}
\dot{\bar{V}}_{i 2}=-a_{e i 2} \bar{V}_{i 2}+b_{e i 2} i_{L} u_{i} \\
\dot{\xi}_{i}=-b_{e i 3} i_{L} u_{i} \\
\bar{V}_{B i}=f\left(\bar{\xi}_{i}\right)-\bar{V}_{i 1}-\bar{V}_{i 2}-b_{r i} i_{L} u_{i}
\end{gathered}
$$

where $\sigma=1$ and $\sigma=2$ designate the forward and the reverse coolant flow, respectively and $T_{f i n} \in\left\{T_{f 0}, T_{f n}\right\}$ is the known fluid temperature in one of the two inlets depending on the direction of the coolant flow. Given that $\left|u_{i}\right|$ in (24) is not continuously differentiable, $u_{i}$ and $\left|u_{i}\right|$ are defined in terms of two new control variables $u_{i 1}$ and $u_{i 2}$ that are defined as $\quad u_{i 1}=\max \left\{0, u_{i}\right\} \in[0,1] \quad$ and $u_{i 2}=\max \left\{0,-u_{i}\right\} \quad \in[0,1] \quad$ respectively. Thus, $u_{i}=\left(u_{i 1}-u_{i 2}\right) \in[-1,1]$ and $\left|u_{i}\right|=\left(u_{i 1}+u_{i 2}\right) \in[0,1] . \quad u_{i 1}$ can then be interpreted as the duty cycle for Mode-1, whereas $u_{i 2}$ can be interpreted as the duty cycle for Mode-2. In this new context, $u_{i 1}$ and $u_{i 2}$ cannot be both nonzero simultaneously (cf. Assumption 1) at any time for safety reasons, which if violated can cause a shoot-through problem. Based on this newly defined control signal, the thermal subsystem of battery $\mathrm{Cell}_{\mathrm{i}}$ for reciprocating coolant flow is given by

$$
\dot{X}_{t i}=a_{t i 1}^{(\sigma)} X_{t 1}+\cdots+a_{t i n}^{(\sigma)} X_{t n}+\hat{g}_{t i}\left(x_{L}\right) \hat{u}_{i}+b_{t i}^{(\sigma)} T_{f i n}
$$

where $X_{t i}=\bar{T}_{s i} \in \mathfrak{R}, \hat{g}_{t i}\left(x_{L}\right)=\left[\begin{array}{ll}b_{s i} x_{L}^{2} & b_{s i} x_{L}^{2}\end{array}\right], \quad \hat{u}_{i}=\left[\begin{array}{ll}u_{i 1} & u_{i 2}\end{array}\right]^{T}$ $\in \mathfrak{R}^{2}$, and $x_{L}=i_{L}$. Similarly, the electrical subsystem of $\mathrm{Cell}_{\mathrm{i}}$ is given by

$$
\dot{X}_{e i}=A_{e i} X_{e i}+\hat{g}_{e i}\left(x_{L}\right) \hat{u}_{i}
$$

where $\quad X_{e i}=\left[\begin{array}{lll}X_{e i 1} & X_{e i 2} & X_{e i 3}\end{array}\right]^{T} \in \mathfrak{R}^{3}$ with $\quad X_{e i 1}=\bar{V}_{i 1}$, $X_{e i 2}=\bar{V}_{i 2} \quad$ and $X_{e i 3}=\bar{\xi}_{i}, \quad A_{e i}=\operatorname{diag}\left(-a_{e i 1},-a_{e i 2}, 0\right)$ $\in \mathfrak{R}^{3 \times 3}$, and $\hat{g}_{e i}\left(x_{L}\right)=\left[\begin{array}{ll}b_{e i} x_{L} & -b_{e i} x_{L}\end{array}\right] \in \mathfrak{R}^{3 \times 2}$ with $b_{e i}=$ $\left[\begin{array}{lll}b_{e i 1} & b_{e i 2} & -b_{e i 3}\end{array}\right]^{T}$.

\section{Complete Averaged State-Space Model of n-Cell MLC}

An n-cell MLC can be represented in various state-space models depending on the number of cells and on the configuration in which they are connected inside each $P C_{i}$. In this model, each $P C_{i}$ is assumed to contain only one Cell $_{i}$. Using equations (29) and (30) as basic building blocks, the state-space system for the thermal subsystem of $n$ cells can be written as follows: 


$$
\dot{X}_{t}=A_{t}^{(\sigma)} X_{t}+\hat{G}_{t}\left(x_{L}\right) \hat{u}+W_{t}^{(\sigma)} T_{f i n}, \quad Y=C_{t} X_{t}
$$

where $A_{t}^{(\sigma)} \in \mathfrak{R}^{n \times n}$ is the system matrix in which $A_{t}^{(1)}$ is the lower triangular matrix with coefficients $a_{t i j}^{(1)}$ defined by equations (11) and (12) for forward coolant flow, $A_{t}^{(2)}=\left(A_{t}^{(1)}\right)^{T}$ is the upper triangular matrix with coefficients $a_{t i j}^{(2)}$ defined by equations (15) and (16) for reverse coolant flow, $\hat{G}_{t}\left(x_{L}\right)=\operatorname{diag}\left(\hat{g}_{t 1}\left(x_{L}\right), \cdots, \hat{g}_{t n}\left(x_{L}\right)\right) \in \mathfrak{R}^{n \times 2 n}$ is the load current-dependent input matrix for the thermal subsystem, $W_{t}^{(\sigma)}=\left[\begin{array}{lll}b_{t 1}^{(\sigma)} & \cdots & b_{t n}^{(\sigma)}\end{array}\right]^{T} \in \mathfrak{R}^{n} \quad$ with coefficients $b_{t i}^{(\sigma)}$ defined by equation (13) for $\sigma=1$ and equation (15) for $\sigma=2$ is the scaling vector for the inlet fluid temperature, $C_{t}=I_{n} \in \mathfrak{R}^{n \times n} \quad$ is the output matrix, $X_{t}=\left[\begin{array}{lll}X_{t 1} & \cdots & X_{t n}\end{array}\right]^{T} \in \mathfrak{R}^{n}$ is the thermal state vector, $\hat{u}=\left[\begin{array}{lll}\hat{u}_{1}^{T} & \cdots & \hat{u}_{n}^{T}\end{array}\right]^{T} \in \mathfrak{R}^{2 n}$ is the input vector, $T_{f i n} \in \mathfrak{R}$ is the known fluid temperature $\left(T_{f 0}\right.$ or $\left.T_{f n}\right)$ in one of two inlets depending on the direction of the coolant flow, and $Y \in \mathfrak{R}^{n}$ is the output vector. Similarly, the electrical subsystem of the n-cells is given by

$$
\dot{X}_{e}=A_{e} X_{e}+\hat{G}_{e}\left(x_{L}\right) \hat{u}
$$

where $A_{e}=\operatorname{diag}\left(A_{e 1}, \cdots, A_{e n}\right) \in \mathfrak{R}^{3 n \times 3 n}$ is the system matrix, $\hat{G}_{e}\left(x_{L}\right)=\operatorname{diag}\left(\hat{g}_{e 1}\left(x_{L}\right), \cdots, \hat{g}_{e n}\left(x_{L}\right)\right) \in \mathfrak{R}^{3 n \times 2 n}$ is the load current-dependent input matrix for the electrical subsystem, $X_{e}=\left[\begin{array}{lll}X_{e 1}^{T} & \cdots & X_{e n}^{T}\end{array}\right]^{T} \in \mathfrak{R}^{3 n}$ is the electrical state vector, and $\hat{u} \in \mathfrak{R}^{2 n}$ is the input vector.

Subsequently, the two subsystems can be combined in diagonal form.

$$
\begin{aligned}
& {\left[\begin{array}{c}
\dot{X}_{t} \\
\dot{X}_{e}
\end{array}\right]} \\
& \underbrace{\left[\begin{array}{cc}
A_{t}^{(\sigma)} & 0 \\
0 & A_{e}
\end{array}\right]}_{\dot{X}} \underbrace{\left[\begin{array}{c}
X_{t} \\
X_{e}
\end{array}\right]}_{A^{(\sigma)}}+\underbrace{\left[\begin{array}{c}
\hat{G}_{t}\left(x_{L}\right) \\
\hat{G}_{e}\left(x_{L}\right)
\end{array}\right]}_{X} \hat{u}+\underbrace{\left[\begin{array}{c}
W_{t}^{(\sigma)} \\
0
\end{array}\right]}_{\hat{G}\left(x_{L}\right)} T_{W^{(\sigma)}} \\
& \dot{X}=A^{(\sigma)} X+\hat{G}\left(x_{L}\right) \hat{u}+W^{(\sigma)} T_{f i n}, \quad Y=C X
\end{aligned}
$$

where $A^{(\sigma)} \in \mathfrak{R}^{4 n \times 4 n}$ is the system matrix, $\hat{G}\left(x_{L}\right) \in \mathfrak{R}^{4 n \times 2 n}$ is the load current-dependent input matrix for the complete system, $C=\left[\begin{array}{ll}C_{t} & 0\end{array}\right] \in \mathfrak{R}^{n \times 4 n}$ is the output matrix, $X \in \mathfrak{R}^{4 n}$ is the state vector, $\hat{u} \in \mathfrak{R}^{2 n}$ is the input vector, and $W^{(\sigma)} \in \mathfrak{R}^{4 n}$ is the scaling vector for the inlet fluid temperature. The averaged state-space electro-thermal model under RF, as shown in equation (33), is a piece-wise affine system.
Remark 1: The control signal $u_{i}$ can be used to determine the modes of $H B_{i}$ and $\mathrm{Cell}_{\mathrm{i}}$ inside each $P C_{i}$ at any time ' $t$ '. The mode in which $H B_{i}$ inside any $P C_{i}$ is operating can be determined by algorithm 1 . Similarly, algorithm 2 can be used to determine the mode of $\mathrm{Cell}_{\mathrm{i}}$ (i.e., whether it is charging or discharging) inside any $P C_{i}$.

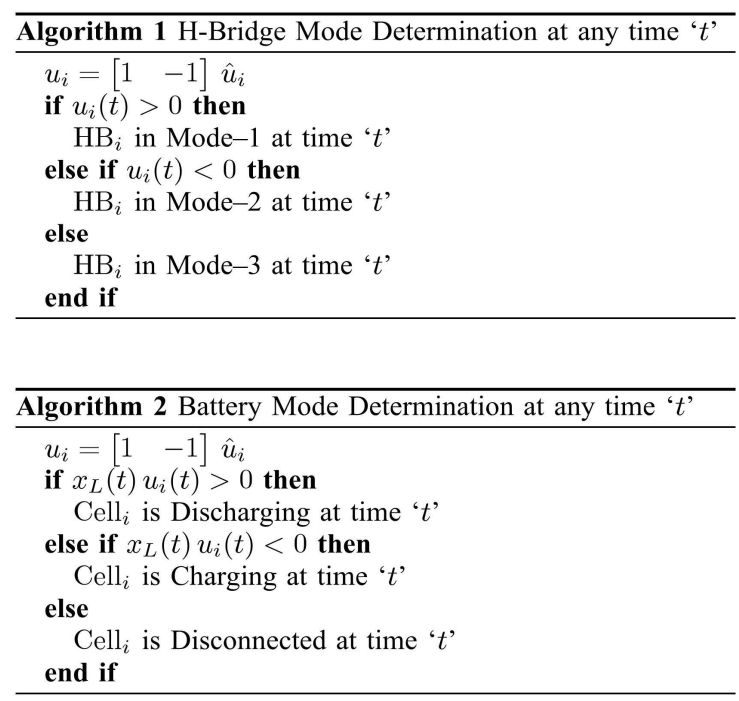

\section{OPTIMIZATION PROBLEM}

In this section, an optimization problem is formulated for the OP scheme to achieve cell balancing in terms of both temperature and SoC. The averaged state-space model derived in the previous section is used along with an objective function and certain constraints as described below.

\section{A. Definition of the Objective Function}

The objective of this study is to equalize $\mathrm{SoC}$ of all cells at the final time and to maintain both $\mathrm{SoC}$ and temperature deviations among the cells within a certain zone during the entire drive cycle. These objectives will be specified as constraints in the next subsection. Another aim is to minimize temperature deviations among the battery cells, as specified in the following objective function:

$$
J(Y)=\int_{0}^{t_{f}}\left(Y_{1}-Y_{2}\right)^{2}+\cdots+\left(Y_{n-1}-Y_{n}\right)^{2} d t
$$

To transform $J(Y)$ into the quadratic form in $X$, $Q=C^{T} \bar{Q}_{1} \bar{Q}_{1}^{T} C \quad$ is $\quad$ defined with $\bar{Q}_{1}=\operatorname{diag}\left(q_{1}, \cdots, q_{n-1}\right) \in \mathfrak{R}^{n \times(n-1)} \quad, \quad$ where $\quad q_{i}=\left[\begin{array}{ll}1 & -1\end{array}\right]^{T}$. Therefore, the objective function (34) can be rewritten as the following standard quadratic form: 


$$
J(X)=\int_{0}^{t_{f}} X^{T} Q X d t
$$

\section{B. Definition of Constraints}

There are some hard (operational, safety and balancing) constraints that need to be respected by $\mathrm{OP}$. The objective of balancing SoC is defined in terms of the following zone and terminal constraints. During run-time, SoC of all cells must stay within a certain zone from each other, as given by

$$
\begin{array}{r}
-\Delta S o C \leq\left(X_{e i 3}(t)-X_{e j 3}(t)\right) \leq \Delta S o C, \\
\forall t, \forall i, j \in\{1,2, \cdots, n\}
\end{array}
$$

and at the final time, $\mathrm{SoC}$ of all cells should be equal:

$$
X_{e i 3}\left(t_{f}\right)=X_{e j 3}\left(t_{f}\right) \quad \forall i, j \in\{1,2, \cdots, n\}
$$

In addition, $\mathrm{SoC}$ of $\mathrm{Cell}_{\mathrm{i}}$ must stay within following zone:

$$
0 \leq X_{e i 3}(t) \leq 1 \forall t, \forall i \in\{1,2, \cdots, n\}
$$

To ensure tight thermal balancing, in addition to minimizing the deviations of cell temperatures, a hard constraint maintains temperature deviations among the cells in the following zone:

$$
-\Delta T_{s} \leq\left(T_{s i}(t)-T_{s j}(t)\right) \leq \Delta T_{s} \quad \forall t, \forall i, j \in\{1, \cdots, n\}
$$

Moreover, a safety constraint on the maximum operating temperature of each cell is present.

$$
T_{s i}(t) \leq T_{s \max } \forall t, \forall i \in\{1,2, \cdots, n\}
$$

where $T_{s \max }$ is the maximum operating temperature allowed for Cell $\mathrm{i}_{\mathrm{i}}$. The objective to track the demanded load voltage $\left(v_{L d}\right)$ can be written as the following constraint

$$
v_{L d}=\sum_{i=1}^{n}\left[\left(f\left(X_{e i 3}\right)-X_{e i 1}-X_{e i 2}\right) u_{i}-b_{r i}\left|u_{i}\right| x_{L}\right]
$$

where $v_{L d}$ is normally provided by the higher supervisory block called energy management system (EMS) in the context of HEVs. $u_{i}=\left[\begin{array}{ll}1 & -1\end{array}\right] \hat{u}_{i}$ represents the duty cycle of Cell $\mathrm{i}_{\mathrm{i}}$. In this study, $f\left(X_{e i 3}\right)$ is assumed to be constant, while $X_{e i 1}$ and $X_{e i 2}$ are negligible, which are normal assumptions in developing EMS for (P)HEVs [30]. These assumptions preserve the convexity of the problem. Moreover, a constraint is identified on the maximum current that each battery cell can supply.

$$
x_{L} u_{i} \in\left[\bar{i}_{B i \min }, \bar{i}_{B i \max }\right]
$$

where $\bar{i}_{B i \text { min }}$ and $\bar{i}_{B i \max }$ are the minimum and the maximum battery current limits, respectively. Certain constraints are also present on the control signal $\hat{u}_{i}=\left[\begin{array}{ll}u_{i 1} & u_{i 2}\end{array}\right]^{T} \in \mathfrak{R}^{2}$, which are given by

$$
u_{i 1} \in[0,1], \quad u_{i 2} \in[0,1], \quad\left|u_{i}\right|=\left(u_{i 1}+u_{i 2}\right) \in[0,1],
$$

$$
\text { and } u_{i}=\left(u_{i 1}-u_{i 2}\right) \in[-1,1]
$$

Based on the definitions of $u_{i 1}$ and $u_{i 2}$ in the previous section, these values cannot be nonzero simultaneously to avoid a shoot-through problem. Thus, the following constraint is imposed to ensure safety:

$$
u_{i 1} u_{i 2}=0
$$

However, the last constraint is non-convex and must be removed to preserve convexity of the problem.

\section{Definition of the Optimization Problem}

The optimization problem can subsequently be written as follows:

$$
\begin{aligned}
J^{0}= & \min _{\hat{u}} \int_{0}^{t_{f}} X^{T} Q X d t \quad \text { subject to } \\
& \left\{\begin{array}{l}
\dot{X}=A^{(\sigma)} X+\hat{G}\left(x_{L}\right) \hat{u}+W^{(\sigma)} T_{f i n} \\
\text { Constraints }(36)-(44), \\
x_{L}(t), T_{f i n} \text { and } \sigma \text { are known at each time step. }
\end{array}\right.
\end{aligned}
$$

The optimization problem (P-I) is non-convex because of the non-convex constraint $u_{i 1} u_{i 2}=0$. In the next subsection, certain assumptions are formulated to restore convexity and to simplify the problem.

\section{Solving the Optimization Problem Using CVX}

The problem (P-I) was solved by CVX, which is a MATLAB-based package for specifying and for solving convex programs [31], [32] and uses a disciplined convex programming ruleset [33]. CVX transforms MATLAB $\AA$ into a modeling language, allowing constraints and objectives to be specified using standard MATLAB expression syntax.

The non-convex constraint $\left(u_{i 1} u_{i 2}=0\right)$ must be removed prior to establishing the optimization problem (P-I) in CVX. In this study, cell balancing is achieved by assuming that the modes of all PCs belong either to set $\{$ Mode-1, Mode- 3 \} or to $\{$ Mode-2, Mode-3\} but not to $\{$ Mode-1, Mode-2\} at any time instant. In other words, it is not allowed at any time instant to charge and to discharge cells simultaneously.

Based on this assumption, the sign of $u_{i 1}$ can be pre-decided based on the sign of a known demanded load voltage $\left(v_{L d}\right)$. Therefore, at $v_{L d} \geq 0, \quad u_{i 2}=0$ and $u_{i}=\left(u_{i 1}-u_{i 2}\right) \geq 0$. Otherwise $u_{i 1}=0$ and consequently, $u_{i} \leq 0$. Therefore, the non-convex constraint $\left(u_{i 1} u_{i 2}=0\right)$ need not be specified. The system was discretized using Euler's approximation at sampling time $h=1 \mathrm{sec}$. The simulation parameters are shown in Table II, 
TABLE II

SiMULATION PARAMETERS

\begin{tabular}{lc|lc}
\hline Parameters & Value & Parameters & Value \\
\hline$n$ & 5 & $\bar{i}_{\text {Bimin }}$ & $-200 \mathrm{~A}, \forall i$ \\
$t_{f}$ & $12 \mathrm{~min}$ & $\bar{i}_{\text {Bimax }}$ & $200 \mathrm{~A}, \forall i$ \\
$h$ & $1 \mathrm{sec}$ & $\Delta T_{s}$ & $2{ }^{\circ} \mathrm{C}$ \\
$N$ & $t_{f} / h=720$ & $\Delta S o C$ & 0.1 \\
$\bar{R}_{s}$ & $6.2770 \mathrm{~m} \Omega$ & $T_{\text {smax }}$ & $40^{\circ} \mathrm{C}$ \\
$R_{s 5}$ or $R_{s 3}$ & $1.48 \bar{R}_{s}=9.29 \mathrm{~m} \Omega$ & $T_{\text {fin }}$ & $20^{\circ} \mathrm{C}$ \\
$T_{s i}(0)$ & $25^{\circ} \mathrm{C}, \forall i$ & $\tau$ & $60 \mathrm{sec}$ \\
\hline
\end{tabular}

where $\bar{R}_{S}$ is the nominal value of series resistance $R_{s i}$ of any $\mathrm{Cell}_{\mathrm{i}}, \quad N$ is the prediction (or driving) horizon in discrete time, and $\tau$ is the reciprocation period or the period in which the coolant completes one cycle of uniform forward and reverse flows.

\section{Simulation RESUlTS}

A few variables must be introduced before the simulation results are presented. These variables are illustrated in plots for more clarity. $\bar{X}_{t i}=\frac{1}{N} \sum_{k=0}^{N} X_{t i}(k)$ is defined as the average temperature of $\mathrm{Cell}_{\mathrm{i}}$ on the entire driving horizon $N$ and $\bar{X}_{t b}=\frac{1}{n} \sum_{i=1}^{n} \bar{X}_{t i}$ is the average temperature of BSM. Similarly, the normalized average power loss per unit ohm across any $\mathrm{Cell}_{\mathrm{i}}$ on the entire driving horizon is given by

$$
\bar{I}_{i}=\frac{\frac{1}{N} \sum_{k=1}^{N} i_{B r_{i}}^{2}(k)}{\max _{j}\left(\frac{1}{N} \sum_{k=1}^{N}\left(i_{B r_{j}}^{o u}(k)\right)^{2}\right)}
$$

where $i_{B r_{j}}^{o u}$ is the RMS current through Cell $\mathrm{j}_{\mathrm{j}}$ for OP under UF, as defined by equation (22). The superscripts "o" and " $u$ " distinguish the signals of OP from UDCO, whereas the superscripts " $u$ " and " $r$ " represent UF and RF, respectively. Fig. 5 shows the drive cycle data comprising the demanded power, voltage, and current profiles used in the simulations. In the following sections, the simulation results of two different cell configurations are presented to thoroughly evaluate the effectiveness of the proposed OP. In configuration-1, the cell with $50 \%$ higher resistance is assumed to be the last downstream cell $\left(\mathrm{Cell}_{5}\right)$ in the five-cell string, whereas in configuration-2, the cell with higher resistance is assumed to be connected in the middle (i.e., at position of $\mathrm{Cell}_{3}$ ) of the string. Both string configurations are discussed separately below to show the implications of OP.

\section{A. Configuration-1: Downstream Cell 5 has higher resistance}

In this subsection, the performances of UDCO and OP under both UF and RF are evaluated. Cell $1_{5}$ is assumed to have
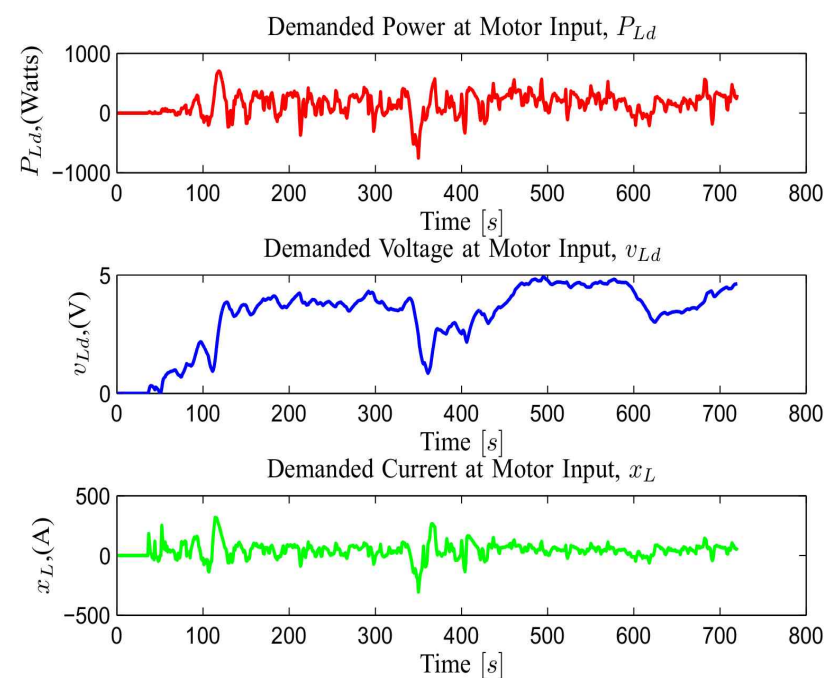

Fig. 5. Drive Cycle: Demanded Power, Voltage, and Current Profile. Two short duration high power peaks exist: (1) around 120 seconds and (2) around 350 seconds.
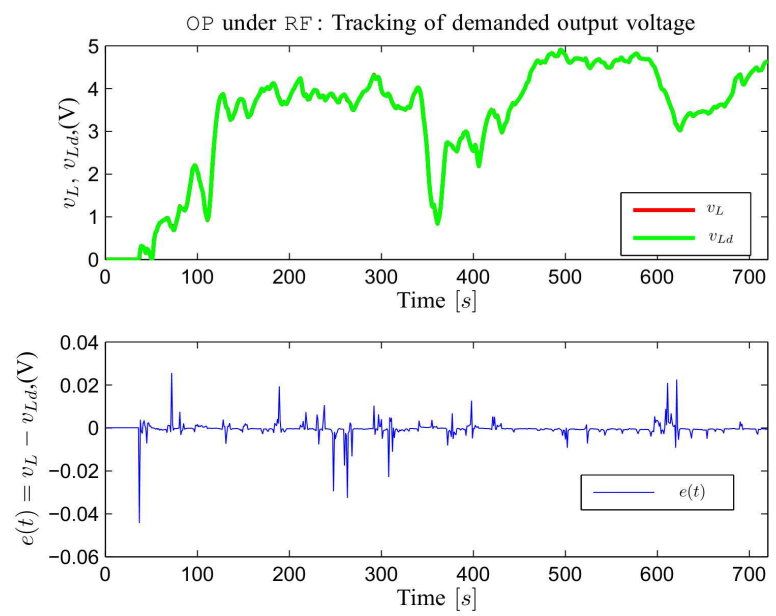

Fig. 6. Tracking of demanded output voltage. The figure shows that OP tracks the demanded output voltage with significantly small error. The tracking performance is the same for string configurations 1 and 2 .

almost $50 \%$ higher series resistance because of aging or of some other effect. The temperature $\left(X_{t i}\right)$, SoC $\left(\xi_{i}\right)$, and the normalized average per unit power loss $\left(\bar{I}_{i}\right)$ are plotted for each cell. Note that the assumption about $50 \%$ increase in internal resistance is not unrealistic as according to [34] the battery internal resistance may vary significantly as a function of its cycle-life. The simulation results are shown for both OP and UDCO in Fig. 7 for RF and in Fig. 8 for UF.

$O P$ versus UDCO under RF: Fig. 6 shows the output voltage generated by MLC and the good tracking performance with a significantly small error for OP. The temperatures of all cells under RF are shown for OP in Fig. 7(a) and for UDCO policy in Fig. 7(b). The temperature of $\mathrm{Cell}_{5}$ under RF for the UDCO policy is significantly higher than that of OP. 


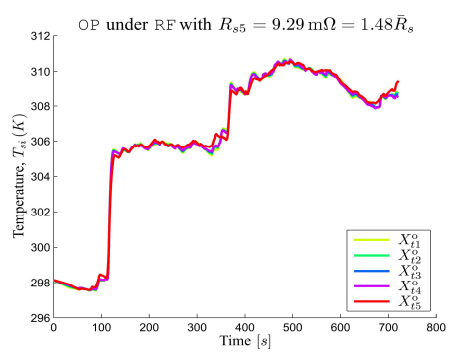

(a) Optimal Temperature of each cell for OP under RF. Despite $R_{s 5}$ being $50 \%$ higher, OP successfully achieved thermal balancing among all cells.

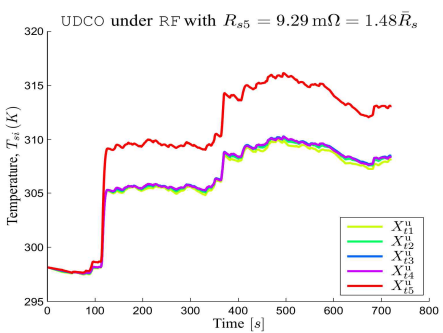

(b) Temperature of each cell for UDCO under RF. Red: Hottest Cell, Light Green: Coldest Cell. Cell $_{5}$ suffers from thermal run away as shown in red.

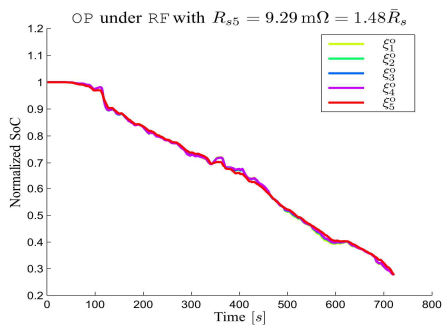

(c) Optimal SoC of each cell for OP under RF. The plot shows that OP has simultaneously achieved SoC and thermal balancing shown in Fig. 7(a).

Fig. 7. Configuration-1 under RF: Simulation results and comparison between OP and UDCO for RF with the most downstream $\mathrm{Cell}_{5}$ having $50 \%$ higher resistance. The plots show that OP significantly performs better than UDCO under RF. The uniform use of cells is naturally not optimal in this situation because the resistance $\left(R_{s 5}\right)$ of $\mathrm{Cell}_{5}$ is $50 \%$ higher than that of the others. The plots also show that using RF is not highly helpful for UDCO under parameter variation. RF only helps to reduce temperature deviation in the cells with nominal resistance, while cells with higher resistance still suffer from thermal run away.

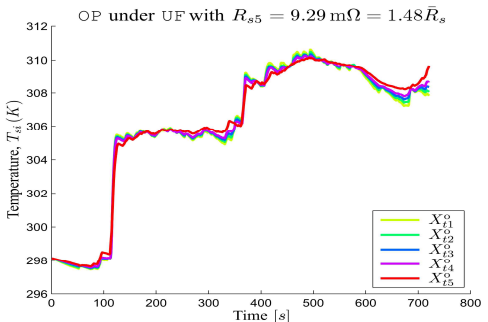

(a) Optimal Temperature of each cell for OP under UF. Despite Rs5 being 50\% higher, OP has successfully achieved thermal balancing among all cells.

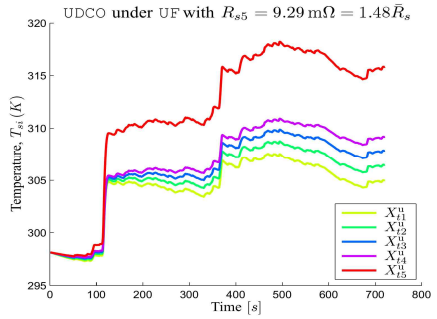

(b) Temperature of each cell for UDCO under UF. Red: Hottest Cell, Light Green: Coldest Cell. Cell 5 suffers from thermal run away as shown in red.

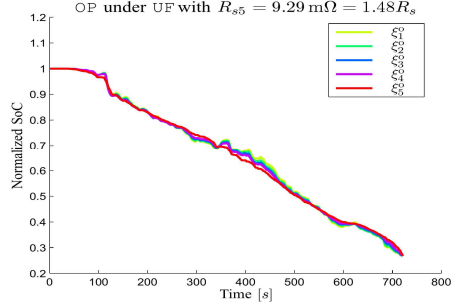

(c) Optimal SoC of each cell for OP under UF. The plot shows that OP has simultaneously achieved SoC and thermal balancing shown in Fig. 8(a).

Fig. 8. Configuration-1 under UF: Simulation results and comparison between OP and UDCO for UF with the most downstream $\mathrm{Cell}_{5}$ having $50 \%$ higher resistance. The plots show that OP significantly performs better than UDCO under UF. The uniform use of cells is naturally not optimal in this situation because the resistance $\left(R_{s 5}\right)$ of the Cell $1_{5}$ is $50 \%$ higher than that of others. Fig. 7 and 8 show that OP exhibits similar performance under UF and RF. Thus, RF is redundant for an MLC-based active cell balancing system when operated using OP.

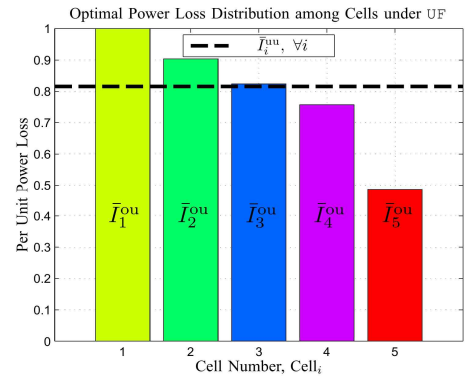

(a) Optimal normalized average power loss per unit ohm across Cell $_{\mathrm{i}}$ for $\mathrm{OP}$ under UF. The dashed horizontal black line shows normalized unit power loss across $\mathrm{Cell}_{\mathrm{i}}$ for UDCO.

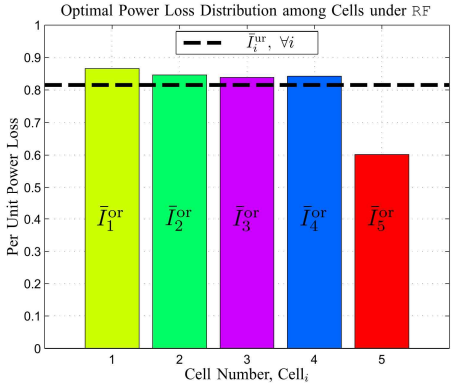

(b) Optimal normalized average power loss per unit ohm across Cell $\mathrm{C}_{i}$ for $\mathrm{OP}$ under RF. The dashed horizontal black line shows normalized unit power loss

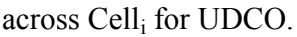

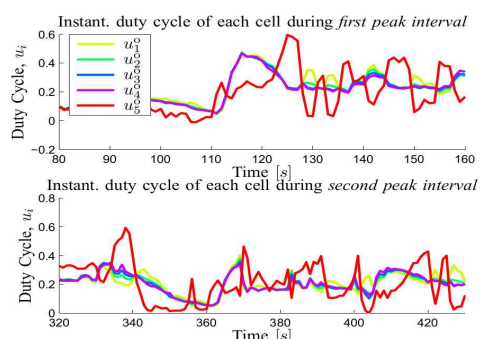

(c) Optimal instantaneous duty cycles for each cell during high current intervals for OP with RF. The plot shows that during high current intervals, OP least uses $\mathrm{Cell}_{5}$ compared with other cells

Fig. 9. Configuration-1 UF versus RF: Optimal power loss distribution under UF and RF. These plots show that during high current intervals, OP least uses Cell $1_{5}$ compared with other cells. Thus, Cell 5 provides less current during high current intervals and consequently, has less losses, as shown in Fig. 9(b). This is naturally optimal as losses are quadratic in current.

Moreover, OP achieved good thermal balancing while maintaining the temperatures of all cells within $\pm 2{ }^{\circ} \mathrm{C}$ and $\mathrm{SoC}$ within $\pm 10 \%$ from each other, as shown in Fig. 7(c). SoC for the UDCO policy is not shown. However, a uniform decay is assumed for each cell. Fig. 9(b) shows the normalized average unit power loss $\bar{I}_{i}$ for each cell under RF. The horizontal dashed black line illustrates the average unit power loss $\bar{I}_{i}^{u}$ 
across each cell for the UDCO policy, whereas the colored vertical bars illustrate the average unit power loss $\bar{I}_{i}^{o r}$ across each cell for the OP scheme. The internal resistance $R_{s 5}$ of $\mathrm{Cell}_{5}$ is almost $50 \%$ higher than that of other cells. Thus, as shown in Fig. 9(b), the naturally optimal policy is the least use of Cell ${ }_{5}$ compared with others and $\mathrm{Cell}_{1}$, under best thermal conditions, should be used most.

OP versus $U D C O$ under $U F$ : The temperatures of all cells are shown for OP in Fig. 8(a) and for UDCO policy in Fig. 8(b) under UF. Fig. 9(a) shows the normalized average unit power loss for each cell under UF. OP again performs better than the UDCO policy, as demonstrated in the figure. Similar to the RF case, OP simultaneously achieved good thermal and SoC balancing by using $\mathrm{Cell}_{5}$, which is the most downstream cell with $50 \%$ higher resistance, least compared with the others whereas Cell ${ }_{1}$ is used most. [20] presents a more detailed comparison between OP and UDCO under UF.

Optimal Power Loss Distributions for UF and RF: Fig. 9(a) and 9 (b) demonstrate the normalized average unit power loss for UF and RF cases, respectively. These figures demonstrate the effect of the coolant flow scheme on optimal decisions of OP. The difference between the average unit power loss in UF and that in RF should be noted, particularly the difference between the optimal power loss distributions for $\mathrm{Cell}_{5}$ in the two cases. In the RF case the $\mathrm{Cell}_{5}$, that is no longer a downstream cell, can benefit from coolant reciprocation. Thus, OP decides to use it almost $10 \%$ more (in terms of losses) than that of the UF case. Although the optimal power loss distribution is different in both cases, the temperature increase of the cells is the same, as shown in Figures 8(a) and 7(a). This similarity indicates that OP automatically handles the coolant flow scheme and decides on the optimal power loss distribution over each cell accordingly. OP likewise handles thermal imbalances caused by resistance variation and by the temperature gradient in the coolant. Fig. 9(a) shows that in the UF case, optimal power loss distribution between two adjacent cells differs by almost $10 \%$ due to the temperature gradient in the coolant. The difference in power loss distribution between two cells is almost $20 \%$ because of the resistance variation. This finding indicates that although the power loss difference due to resistance variations is large, power loss due to the coolant temperature gradient is also not negligible. Thus, active thermal balancing is still necessary to compensate for the temperature gradient in the coolant though no resistance variation occurs in the battery string. In recollection, no decision is ad hoc here, everything is handled systematically by solving the model-based optimization problem (P-I).

\section{B. Configuration-2: Middle Cell ${ }_{3}$ has higher resistance}

In this subsection, the performances of UDCO and OP under both UF and RF are evaluated for configuration-2 of the five-cell string. In this case, the middle $\mathrm{Cell}_{3}$, instead of $\mathrm{Cell}_{5}$, is assumed to have almost $50 \%$ higher series resistance. The temperature $\left(X_{t i}\right)$, SoC $\left(\xi_{i}\right)$, and the normalized average per unit power loss $\left(\bar{I}_{i}\right)$ are plotted for each cell. Simulation results are shown for both OP and UDCO in Fig. 10 for RF and in Fig. 11 for UF. The drive cycle data is the same as those presented previously (Fig. 5).

OP versus UDCO under RF: Fig. 10(a) and 10(c) show the temperatures and SOC of all cells for OP under RF. Fig. 10(b) exhibits the temperature for the UDCO policy under RF. The temperature of $\mathrm{Cell}_{3}$ for the UDCO policy is significantly higher under RF than that of $\mathrm{OP}$ in this configuration. Moreover, OP simultaneously achieved good thermal and SoC balancing while satisfying all constraints. Fig. 12(b) shows the normalized average unit power loss $\bar{I}_{i}$ that is optimally decided by OP for each cell. The internal resistance $R_{s 3}$ of $\mathrm{Cell}_{3}$ is almost $50 \%$ higher than that of other cells. Thus, the natural OP least uses $\mathrm{Cell}_{3}$ compared with other cells, and $\mathrm{Cell}_{1}$ and $\mathrm{Cell}_{5}$, under the best thermal conditions for the RF case, are used more.

OP versus UDCO under UF: Fig. 11(a) and 11(b) show the temperatures of all cells for OP and for the UDCO policy, respectively. Fig. 12(a) presents the normalized average unit power loss for each cell under UF. As shown in the figures, OP performs better than UDCO. Similar to that in the RF case, OP simultaneously achieved good thermal and SoC balancing for this cell configuration by using $\mathrm{Cell}_{3}$ least and Cell $l_{1}$ the most compared with other cells, as shown in Fig. 12(a).

Optimal Power Loss Distributions for UF and RF: Fig. 12(a) and 12(b) display the normalized average unit power loss for UF and for RF cases, respectively. These figures indicate the effect of the coolant flow scheme on the optimal decisions of OP. The optimal power loss distributions for $\mathrm{Cell}_{3}$ in this configuration are relatively similar in both UF and RF cases. Given that $\mathrm{Cell}_{3}$ is the middle cell, reciprocation has a slight influence on the optimal power loss decision of OP for this cell.

\section{DISCUSSION}

In this section, some important implications of the simulation results are discussed.

\section{A. Benefits of Reciprocating Air Flow}




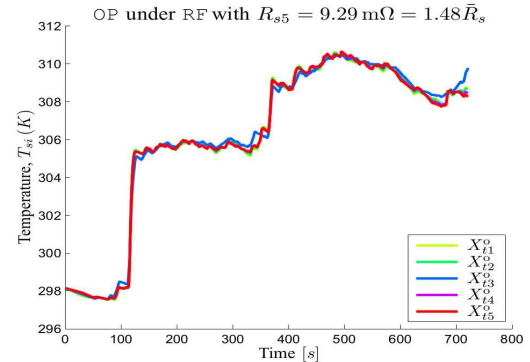

(a) Optimal Temperature of each cell for OP under RF.

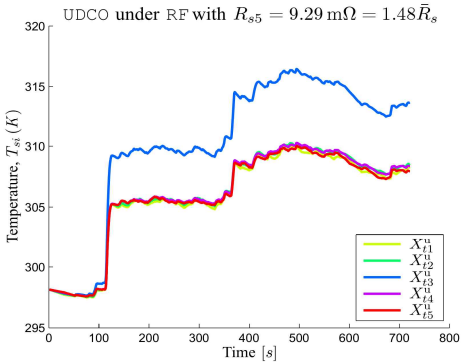

(b) Temperature of cells for UDCO under RF. Cell ${ }_{3}$ has higher temperature.

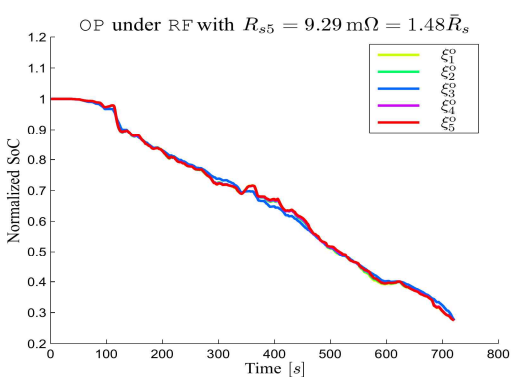

(c) Optimal SoC of each cell for OP under RF.

Fig. 10. Configuration-2 under RF: Simulation results and comparison between OP and UDCO for RF with middle Cell ${ }_{3}$ having $50 \%$ higher resistance. The plots show that OP significantly performs better than UDCO under RF. The Fig. 10(b) shows that using $\mathrm{RF}$ is not very helpful for UDCO under parameter variations.

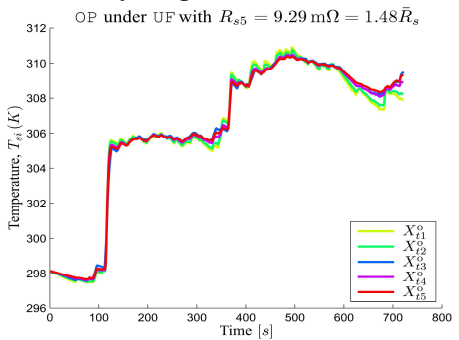

(a) Optimal Temperature of each cell for OP under UF.

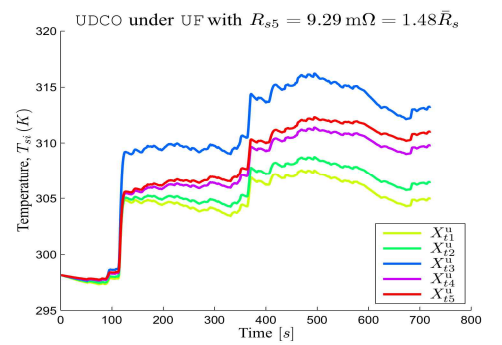

(b) Temperature of each cell for UDCO under UF.

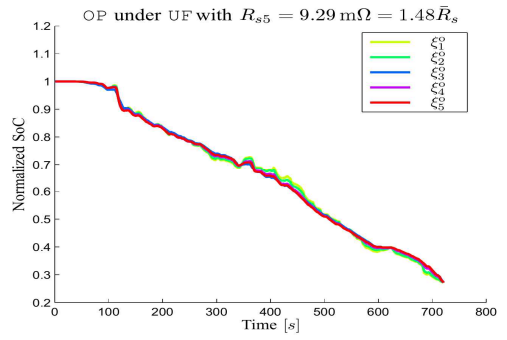

(c) Optimal SoC of each cell for OP under UF.

Fig. 11. Configuration-2 under UF: Simulation results and comparison between OP and UDCO for UF with middle Cell ${ }_{3}$ having $50 \%$ higher resistance. The plots show that OP significantly performs better than UDCO under UF as well.

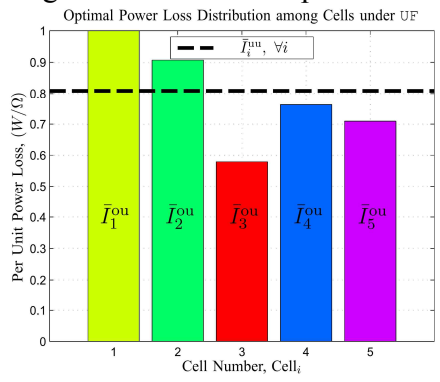

(a) Optimal normalized average power loss per unit ohm across $\mathrm{Cell}_{\mathrm{i}}$ for $\mathrm{OP}$ under UF.

Fig. 12. Configuration-2 UF versus RF: Optimal power loss distribution under UF and RF. These plots show that during high current intervals, OP least uses $\mathrm{Cell}_{3}$ compared with other cells. Thus, Cell 3 sees less current during high current interval and consequently, has less losses, as shown in Fig. 12(b). This is naturally optimal as losses are quadratic in current.
In this section, UF and RF are compared for both OP and UDCO. The temperatures of the cells for the UDCO policy under UF are shown in Fig. 8(b) for configuration-1 and in Fig. 11(b) for configuration-2. The temperatures of the cells for the UDCO policy under RF are exhibited in Fig. 7(b) for configuration-1 and in Fig. 10(b) for configuration-2. Similarly, the temperatures of the cells for OP under UF are shown in Fig. 8(a) for string configuration-1 and in Fig. 11(a) for string configuration-2. The temperatures of the cells for OP under RF are shown in Fig. 7(a) for string configuration-1 and in Fig. 10(a) for string configuration-2. These figures clearly show that OP has no significant gain when using RF, particularly for short series-connected battery string. The main purpose of RF is merely to achieve temperature uniformity. Using RF with the UDCO policy minimizes temperature deviations among cells with nominal resistance. However, it is not that useful for $\mathrm{Cell}_{5}$ or $\mathrm{Cell}_{3}$ that has $50 \%$ higher resistance. These figures clearly indicate that RF without OP can bring temperature uniformity only in the string having cells with same resistances. Moreover, the temperature gradient in the coolant under RF is negligible only for short strings of cells. For long strings, RF generally cannot remove this gradient completely. Thus, RF alone cannot solve the temperature non-uniformity problem in battery packs of EV/HEV/PHEV because these battery packs normally have long strings of cells with high possibility of having resistance differences. 
However, the temperature uniformity under said conditions can be achieved by optimally shifting the power losses among the cells using MLC-based OP even under UF. Thus in the presence of $\mathrm{OP}, \mathrm{RF}$ is a redundant function.

\section{B. Configuration-1 versus Configuration-2}

In this subsection, the optimal power loss distribution for two string configurations is compared. Fig. 9(b) and 12(b) show that changing the position of the higher resistance cell in the string has slight influence on the power loss distribution in the RF case. However, the influence may be more noticeable in longer battery strings. In the case of UF, changing the position of the higher resistance cell always influence optimal decisions on power loss distribution. This finding can be validated by comparing the optimal power loss distributions of $\mathrm{Cell}_{5}$ and of $\mathrm{Cell}_{3}$ in Fig. 9(a) and 12(a). The difference in power loss compensates for the temperature gradient in the coolant for the UF case.

A difference can be observed in the temperature dynamics for the two configurations under the UDCO policy, as illustrated in Fig. 11(b) and 8(b). This difference is due to higher resistance $\mathrm{Cell}_{3}$ in the middle of the string for configuration-2, thereby generating more heat that results in higher temperature differential between $\mathrm{Cell}_{2}$ and $\mathrm{Cell}_{3}$. Meanwhile, temperatures of $\mathrm{Cell}_{1}$ to $\mathrm{Cell}_{4}$ for configuration-1 are distributed in a staircase fashion because of uniform temperature gradient in the coolant. However, the temperature evolution of the two configurations is almost the same under OP, as shown in Fig. 11(a) and 8(a).

\section{Working of OP in a nutshell}

OP achieves thermal balancing by least using $\mathrm{Cell}_{5}$ (or $\mathrm{Cell}_{3}$ ) compared with other cells during high current intervals, as shown in Fig. 9(c) (or Fig. 12(c)). Thus, $\mathrm{Cell}_{5}$ (or $\mathrm{Cell}_{3}$ ) has less ohmic losses. This policy is naturally optimal as losses are quadratic in current. In a nutshell, OP achieves thermal balancing by avoiding the use of higher resistance cells during peak power intervals and by using the cell more frequently during low power intervals. Moreover, similarities can be observed between the optimal duty cycles of the switches in two different string configurations, as shown in Fig. 9(c) and $12(\mathrm{c})$.

\section{SUMMARY AND CONCLUSIONS}

This article investigated the potential benefit of optimally using the extra DoF of MLC for simultaneous balancing of SoC and temperature of cells under UF and RF. A complete state-space electro-thermal model was developed and a constrained convex optimization problem was formulated and solved based on the assumption that the state of each cell and the schedule of reciprocating air flow are perfectly known. The simulation results showed that at $50 \%$ increase in internal resistance of any cell, OP optimally uses the extra DoF of MLC, significantly reducing temperature deviation among the cells compared with the ad hoc uniform duty cycle operation. In a nutshell, OP achieves thermal balancing by optimally shifting the power losses among the cells depending on their resistance and positions in the string. Thus, OP can also achieve temperature uniformity under parameter variations even with UF, whereas RF cannot maintain temperature uniformity in such circumstances without OP. This study shows that using RF has no significant benefit when using an MLC-based OP. Thus, RF is considered a redundant function when an MLC-based active cell balancing system is operated using OP.

\section{ACKNOWLEDGMENT}

The authors would like to thank Nikolce Murgovski, Anders Grauers, Oskar Josefsson and Torbjörn Thiringer for all the positive discussions while developing this work. This work was supported by the Chalmers Energy Initiative.

\section{REFERENCES}

[1] B. I. Bloom, J. S. Cole, S. Jones, E. Polzin, V. Battaglia, G. Henriksen, C. Motloch, R. Richardson, T. Unkelhaeuser, D. Ingersoll, and $\mathrm{H}$. Case, "An accelerated calendar and cycle life study of li-ion cells," Journal of Power Sources, Vol. 101, No. 2, p. 238-247, Oct. 2001.

[2] B. Kuhn, G. Pitel, and P. Krein, "Electrical properties and equalization of lithium-ion cells in automotive applications," in Vehicle Power and Propulsion, 2005 IEEE Conference, p. 5, Sep. 2005.

[3] S. Lukic, J. Cao, R. Bansal, F. Rodriguez, and A. Emadi, "Energy storage systems for automotive applications," IEEE Trans. Ind. Electron., Vol. 55, No. 6, pp. 2258-2267, Jun. 2008.

[4] K. Smith, T. Markel, K. Gi-Heon, and A. Pesaran, "Design of electric drive vehicle batteries for long life and low cost," Accelerated Stress Testing and Reliability (ASTR), IEE Workshop on, Oct. 6-8 2010

[5] T. Reddy, Linden's Handbook of Batteries, 4th Edition, 4th ed. McGraw-Hill Professional, 102010.

[6] W. C. Lee, D. Drury, and P. Mellor, "Comparison of passive cell balancing and active cell balancing for automotive batteries," in Vehicle Power and Propulsion Conference (VPPC), 2011 IEEE, pp. 1-7, Sep. 2011.

[7] J. Cao, N. Schofield, and A. Emadi, "Battery balancing methods: A comprehensive review," in Vehicle Power and Propulsion Conference, 2008. VPPC '08. IEEE, pp. 1-6, Sep. 2008.

[8] W. Bentley, "Cell balancing considerations for lithium-ion battery sys-tems," in Battery Conference on Applications and Advances, 1997., 12th Annual, pp. 223-226, Jan. 1997.

[9] P. Krein, "Battery management for maximum performance in plug-in electric and hybrid vehicles," in Vehicle Power and Propulsion Conference, 2007. VPPC 2007. IEEE, pp. 2-5, Sep. 2007

[10] C. Park and A. Jaura, "Reciprocating battery cooling for hybrid and fuel cell vehicles," ASME International Mechanical Engineering Congress and Exposition 
(IMECE2003), Washington, DC, USA, pp. 425-430, Nov. 2003.

[11] _ - "Dynamic thermal model of Li-Ion battery for predictive behavior in hybrid and fuel cell vehicles," $S A E$ transactions, Vol. 112, No. 3, pp. 1835-1842, 2003.

[12] _ _ "Transient heat transfer of $42 \mathrm{~V} \mathrm{Ni-MH}$ batteries for an HEV application," Future Car Congress, 2002.

[13] A. Pesaran and B. S. Vlahinos, A, "Thermal performance of EV and HEV battery modules and packs," Proceedings of the 14th International Electric Vehicle Symposium, Orlando, Florida, Dec. 1997.

[14] R. Mahamud and C. Park, "Reciprocating air flow for li-ion battery thermal management to improve temperature uniformity," Journal of Power Sources, Vol. 196, No. 13, pp. 5685 - 5696, Jul. 2011.

[15] C. Motloch, J. Christophersen, J. Belt, R. Wright, G. Hunt, T. Tartamella, H. Haskins, and T. Miller, "High-power battery testing procedures and analytical methodologies for HEV's," SAE 2002-01-1950, 2002.

[16] J. Rodriguez, L. Franquelo, S. Kouro, J. Leon, R. Portillo, M Prats, and M. Perez, "Multilevel converters: An enabling technology for high-power applications," Proceedings of the IEEE, Vol. 97, No. 11, pp. 1786-1817, Nov. 2009.

[17] M. Malinowski, K. Gopakumar, J. Rodriguez, and M. Pe andrez, "A survey on cascaded multilevel inverters," IEEE Trans. Ind. Electron., Vol. 57, No. 7, pp. 2197-2206, Jul. 2010.

[18] L. Tolbert, F. Z. Peng, and T. Habetler, "Multilevel con verters for large electric drives," IEEE Trans. Ind. Appl., Vol. 35, No. 1, pp. 36-44, Jan./Feb. 1999.

[19] O. Josefsson, A. Lindskog, S. Lundmark, and T. Thiringer, "Assessment of a multilevel converter for a PHEV charge and traction application," in Electrical Machines (ICEM), 2010 XIX International Conference on, pp. 1-6, Sep. 2010.

[20] F. Altaf, L. Johannesson, and B. Egardt, "Evaluating the potential for cell balancing using a cascaded multi-level converter using convex optimization," in IFAC Workshop on Engine and Powertrain Control, Simulation and Modeling, 2012, Oct. 2012.

[21] F. Altaf, L. Johannesson, and B. Egardt, "Performance evaluation of multilevel converter based cell balancer with reciprocating air flow," in Vehicle Power and Propulsion Conference (VPPC), 2012 IEEE, pp. 706-713, Oct. 2012.

[22] J. Rawlings, "Tutorial overview of model predictive control," IEEE Contr. Syst., Vol. 20, No. 3, pp. 38-52, Jun. 2000.

[23] N. Mohan, T. M. Undeland, and W. P. Robbins, Power Electronics: Converters, Applications, and Design, 3rd ed. John Wiley \& Sons, 2003.

[24] F. Codeca, S. Savaresi, and G. Rizzoni, "On battery state of charge estimation: A new mixed algorithm," in Control Applications, 2008. CCA 2008. IEEE International Conference on, pp. 102-107, Sep. 2008.

[25] M. Chen and G. Rincon-Mora, "Accurate electrical battery model capable of predicting runtime and i-v performance," IEEE Trans. Energy Convers., Vol. 21, No. 2, pp. 504-511, Jun. 2006

[26] H. He, R. Xiong, X. Zhang, F. Sun, and J. Fan, "State-of-charge estimation of the lithium-ion battery using an adaptive extended kalman filter based on an improved thevenin model," IEEE Trans. Veh. Technol., Vol. 60, No. 4, pp. 1461-1469, may 2011.

[27] H. Khalil, Nonlinear systems. Prentice Hall, NJ, 2002.

[28] J. Kassakian, M. Schlecht, and G. Verghese, Principles of Power Electronics. Addison-Wesley, 1991.
[29] S. Sirisukprasert, "The modeling and control of a cascaded-multilevel converter-based STATCOM," $\mathrm{PhD}$ Thesis, Virginia Tech, 2004.

[30] L. Guzzella and A. Sciarretta, Vehicle Propulsion Systems. Springer, 2005.

[31] M. Grant and S. Boyd, "CVX: Matlab software for disciplined convex programming, version 1.21,” ../../cvx, Apr. 2011.

[32] — "Graph implementations for nonsmooth convex programs," in Recent Advances in Learning and Control, ser. Lecture Notes in Control and Information Sciences, V. Blondel, S. Boyd, and H. Kimura, Eds. Springer-Verlag Limited, 2008, pp. 95-110, http://stanford.edu/ boyd/graph dcp.html.

[33] S. Boyd and L. Vandenberghe, Convex Optimization. Cambridge University Press, 2006.

[34] D. Andrea, Battery Management Systems for Large Lithium Ion Battery Packs, 1st ed. Artech House, 92010.

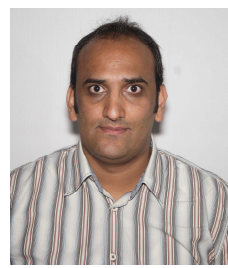

Faisal Altaf was born in Abbottabad, Pakistan. He received his $\mathrm{BE}$ degree in Mechatronics in 2004 from the National University of Sciences \& Technology (NUST) in Pakistan and his M.Sc. degree in Systems, Control and Robotics in 2011 from the KTH Royal Institute of Technology in Sweden. From 2004 to 2008, he worked as a Control Design Engineer for a radar project in the Electrical Engineering Department at NUST. His interdisciplinary role in a team included designing several electronic control circuits and electromechanical components for a complete system. From 2010 to 2011, he was a Research Engineer at the Automatic Control Laboratory in KTH in Sweden. He is currently a PhD student in the Automatic Control division of the Chalmers University of Technology in Sweden and is involved in a project on hybrid electric vehicle systems within the Chalmers Energy Initiative since 2011. His main areas of interest include model-based control design, convex optimization, and optimal control and their applications to power electronic-switched systems for active cell balancing in EV/HEV/PHEVs for performance optimization of battery management systems.

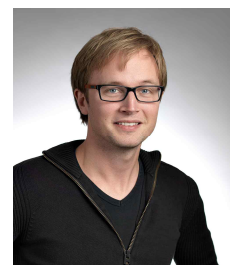

Lars Johannesson received his M.Sc. degree in Automation and Mechatronics and his Ph.D. in Automatic Control from the Chalmers University of Technology in Göteborg, Sweden in 2004 and in 2009, respectively. He has been with the Electromobility group at the Viktoria Swedish ICT since 2011, where he is presently conducting a research on powertrain control within the Chalmers Energy Initiative. His main research interests are optimal control of hybrid and plug-in hybrid electric vehicles, control of auxiliary systems in trucks, active cell balancing, and system studies of hybrid vehicles. He is a member of IEEE. 
Bo Egardt received his M.Sc. degree in Electrical Engineering and his Ph.D. in Automatic Control from the Lund Institute of Technology in Lund, Sweden, in 1974 and in 1979, respectively. During 1980, he was a Research Associate at the Information Systems Laboratory in Stanford, CA. From 1981 to 1989 , he was with Asea Brown Boveri where he was heavily involved in the introduction of adaptive control in the process industry. In 1989, he was appointed Professor of Automatic Control at the Chalmers University of Technology in Göteborg, Sweden. His main areas of interest include adaptive and hybrid control, as well as applications of control in the automotive area. He has been an Associate Editor of the IEEE Transactions on Control Systems Technology and the European Journal of Control. He is a member of the editorial board for the International Journal of Adaptive Control and Signal Processing. He is a Fellow of IEEE. 